\title{
Patients with Barcelona Clinic Liver Cancer Stages B and C Hepatocellular Carcinoma: Time for a Subclassification
}

\author{
Rita Golfieri $^{a} \quad$ Irene Bargellini ${ }^{b} \quad$ Carlo Spreafico $^{c} \quad$ Franco Trevisani $^{d}$ \\ aRadiology Unit, Department of Diagnostic and Preventive Medicine, S. Orsola-Malpighi \\ Hospital, Alma Mater Studiorum - University of Bologna, Bologna, Italy; ${ }^{\text {b Interventional }}$ \\ Radiology Unit, Pisa University Hospital, Pisa, Italy; ' Interventional Radiology Unit, \\ Department of Radiology, Istituto Tumori of Milan IRCCS Foundation, Milan, Italy; ${ }^{d}$ Division \\ of Semeiotics, Department of Medical and Surgical Sciences, Alma Mater Studiorum, \\ Bologna, Italy
}

\section{Keywords}

Liver neoplasms · Intermediate-stage hepatocellular carcinoma · Advanced-stage hepatocellular carcinoma - Portal vein thrombosis · Subclassifications of Barcelona Clinic Liver Cancer stages B and C

\begin{abstract}
Background: The Barcelona Clinic Liver Cancer (BCLC) intermediate and advanced stages (BCLC B and C) of hepatocellular carcinoma (HCC) both include heterogeneous populations. Patients classified as BCLC stage B present with different tumour burdens, and the recommended treatment is transarterial chemoembolization (TACE). A similar heterogeneity of tumour burden and liver function can be found among patients classified as BCLC stage $C$, which includes diverse clinical features (performance status [PS] 1-2), macrovascular invasion (MVI) including portal vein tumour (PVT) thrombosis, and/or extra-hepatic spread. Nonetheless, the anti-tumoural treatment formally recommended by Western guidelines is systemic therapy with sorafenib. Summary: Several proposals of subclassification for both these stages have been suggested in recent years, differentiating the more appropriate treatments for each substage. In particular, for BCLC stage C patients with PVT, therapeutic indications, clinical outcomes, and response to locoregional therapy are notably different in the presence of subsegmental, segmental or main PVT. Accordingly, liver resection and transarterial therapies, such as TACE or transarterial embolization (TAE) and ${ }^{90} \mathrm{Y}$-radioembolization (TARE), can be performed in locally advanced HCC with intrahepatic MVI according to its extent. In fact, surgery and TACE/TAE/TARE have no contraindications in the presence of PVT limited to the subseg-
\end{abstract}


mental or segmental branches in Child-Pugh class A patients, whereas only TARE should be utilized when there is lobar branch involvement. The presence of PS 1 should not be sufficient to allocate patients to the advanced stage since this would preclude any potential treatment for HCC. Patients should be properly classified as BCLC C only in cases of main portal trunk PVT, and treated according to the guidelines, provided that they belong to Child-Pugh class A. Key Messages: Subclassifications of BCLC B and C stages are urgently needed and require validation in order to guide clinicians towards the most effective treatment option.

(C) 2018 S. Karger AG, Base

In Western countries, the most commonly used staging system for establishing prognosis and determining the choice of treatment for hepatocellular carcinoma (HCC) is the Barcelona Clinic Liver Cancer (BCLC) system, originally proposed in 1999 [1] and subsequently updated [2-4]. It contains 5 stages: very early, early, intermediate, advanced, and terminal, according to variables related to tumour burden, liver function (Child-Pugh class), clinical status, and cancer-related symptoms (Eastern Cooperative Group Performance Status [ECOG PS]) [2-4]. The BCLC staging system has been externally validated in different clinical settings [5-7] and has been endorsed by the guidelines for HCC management of the American Association for the Study of Liver Diseases (AASLD), the American Gastroenterology Association (AGA), the European Association for the Study of Liver (EASL), and the European Organization for Research and Treatment of Cancer (EORTC) $[8,9]$.

The main objective of the staging systems is to categorize patients into subgroups having significantly different outcomes [2]. In this respect, the wide range of survival reported in both intermediate- (stage $\mathrm{B}$ ) and advanced-stage (stage $\mathrm{C}$ ) patients indicates that this goal is not achieved by the BCLC classification. Moreover, it has been reported that, in tertiary referral centres, deviations from BCLC therapeutic recommendations occur in up to $50 \%$ of patients. These shortcomings suggest that subclassifications are urgently needed for achieving better prognostic performance, for proposing an updated guide for proper intervention, and for benchmarking the results of the different interventional options.

\section{Intermediate Stage (BCLC B)}

HCC includes a wide population, extending from near-early-stage patients (frequently treatable with curative intent) to near-advanced-stage patients, such as those with a ChildPugh score of 8-9 (poor candidates for transarterial treatments and, if not included in a liver transplant program according to expanded criteria, can only be treated with best supportive care [BSC]). Therefore, even though transarterial chemoembolization (TACE) is the only recommended treatment, not all patients benefit from TACE to the same degree [10-12]. Compared to a median survival of 10-13 months or $49 \%$ at 2 years in untreated patients [13], survival after TACE is extremely heterogeneous, ranging from 36 to 45 months for the best responders to 11 months for the worst scenario $[9,14]$. Such heterogeneity has prompted authors to identify prognostic parameters and scores enabling patients' stratification after TACE [15]. Meanwhile, the subclassification of the intermediate-stage group and the design of treatment strategies specific for each substage have become a topic of great interest.

In 2012, a panel of experts [16] proposed a subclassification which identified four substages (B1-B4) of intermediate HCC, incorporating the new concept of joint consideration of the tumour burden according to the "beyond Milan" and the "within up-to-7" criteria together with the Child-Pugh score and PS (Table 1). Bolondi et al. [16] advised TACE as the first option for B1 patients due to their rather limited tumour bulk and substantially preserved 
Golfieri et al.: Patients with Barcelona Clinic Liver Cancer Stages B and C Hepatocellular Carcinoma: Time for a Subclassification

Table 1. The Bolondi et al. substaging system and treatment indications for intermediate and "quasi advanced" stages [13]

\begin{tabular}{|c|c|c|c|c|c|}
\hline Intermediate substage & B1 & B2 & B3 & B4 & Quasi C \\
\hline Child-Pugh score & $5-7$ & $5-6$ & 7 & $8-9^{a}$ & A \\
\hline $\begin{array}{l}\text { Beyond Milan criteria and within } \\
\text { the up-to- } 7 \text { criteria }\end{array}$ & in & out & out & any & any \\
\hline $\begin{array}{l}\text { ECOG performance status } \\
\text { (tumour-related) }\end{array}$ & 0 & 0 & 0 & $0-1$ & 0 \\
\hline Portal vein tumour thrombosis & no & no & no & no & $\begin{array}{l}\text { yes (segmental or } \\
\text { subsegmental) }\end{array}$ \\
\hline 1st option & TACE & TACE or TARE & research trial & $\mathrm{LT}^{\mathrm{b}}$ & sorafenib \\
\hline Alternative & $\begin{array}{l}\text { LT } \\
\text { TACE + ablation }\end{array}$ & sorafenib & $\begin{array}{l}\text { TACE } \\
\text { sorafenib }\end{array}$ & & TACE or TARE \\
\hline $\begin{array}{l}\text { Median survival time, months } \\
\text { (from Ha et al. [20]) }\end{array}$ & 41.0 & 22.1 & 14.1 & 17.2 & \\
\hline
\end{tabular}

ECOG, Eastern Cooperative Group Performance Status; LT, liver transplantation; SOR, sorafenib; TACE, transarterial chemoembolization; TARE, transarterial radioembolization. ${ }^{a}$ With severe/refractory ascites and/or jaundice. ${ }^{\mathrm{b}}$ Only if "up-to-7 IN" and PS 0.

hepatic function. They also proposed liver transplantation as a possible option in subjects fulfilling the up-to-7 criteria since it could provide longer life expectancy than TACE [17]. Nevertheless, it is under debate why liver transplantation (a curative treatment) has not been proposed as the first-line approach for B1 patients, instead indicating TACE (a palliative treatment) as an alternative choice for those beyond the up-to-7 criteria. The authors stated that the addition of local ablation to TACE also seemed to be effective in this substage. Although TACE was also the recommended first-line therapy for B2 patients, ${ }^{90}$ Y-radioembolization (TARE) or sorafenib should be considered in cases that are expected to be resistant to or have contraindications to conventional TACE $[18,19]$. For the B3 substage, the first suggestion was to test new treatments under well-controlled conditions (clinical trials). Alternatively, TACE or sorafenib were formally suggested. Liver transplantation was considered to be the best option in substage B4 patients provided they met the up-to-7 criteria; otherwise, they should receive symptomatic treatment to avoid unnecessary suffering from liver damage outweighing any anti-tumour effect of specific procedures [17].

Following the article by Bolondi et al. [16], in 2014, Ha et al. [20] validated the model by examining 466 BCLC B patients undergoing TACE. These authors developed a modified subclassification in which B3 and B4 subclasses were merged as BIII while BI and BII corresponded to B1 and B2 of the Bolondi model. Median survival significantly differed between the three subclasses ( 41.0 vs. 22.1 vs. 16.6 months, $p \leq 0.001$ ), confirming the fact that this modification would be an effective tool for stratifying the heterogeneous population encompassed by the BCLC B stage and providing the rationale for a per-subclass-based treatment choice.

An additional validation of the Bolondi et al. substage comes from a retrospective study which included 269 untreated HCC patients from the Italian Liver Cancer (ITA.LI.CA) Group [13]. In these patients, median survival progressively decreased from stage B1 ( $n=65,24.2 \%$; 25 months) to stages B2 ( $n=105,39.0 \%$; 16 months), B3 ( $n=22,8.2 \%$; 9 months), and B4 ( $n=77,28.6 \%$; 5 months; $p<0.0001$ ). 


\section{Liver Cancer}

Table 2. The Kim et al. proposal of a new classification for the intermediate stage [20]

\begin{tabular}{l|l}
\hline Liver Cancer 2019;8:78-91 \\
\hline DOI: 10.1159/000489791 & $\begin{array}{l}\text { @ 2018 S. Karger AG, Basel } \\
\text { www.karger.com/lic }\end{array}$ \\
\hline
\end{tabular}

Golfieri et al.: Patients with Barcelona Clinic Liver Cancer Stages B and C Hepatocellular Carcinoma: Time for a Subclassification

\begin{tabular}{lllll}
\hline BCLC substage & B1 & B2 A & B2 B & B3 \\
\hline Child-Pugh class & A & A & B & B \\
Within up-to-11 & in & out & in & out \\
ECOG PS (tumour related) & 0 & 0 & 0 & 0 \\
Portal vein thrombosis & no & no & no & no \\
\hline
\end{tabular}

BCLC, Barcelona clinic liver cancer; ECOG, Eastern Cooperative Group performance status.

\begin{tabular}{|c|c|c|c|}
\hline Intermediate substage & B1 & B2 & B3 \\
\hline Child Pugh score & $5-6$ & $5-8$ & 9 \\
\hline 4-of-7-cm criterion & in & $\begin{array}{l}\text { in (CP 7-8) } \\
\text { out (CP 5-8) }\end{array}$ & any \\
\hline Treatment option & RFA & TACE & $\begin{array}{l}\text { HAIC } \\
\text { LT }\end{array}$ \\
\hline Alternative & $\begin{array}{l}\text { TACE } \\
(+\mathrm{RFA})\end{array}$ & $\begin{array}{l}\text { HAIC } \\
\text { SOR }\end{array}$ & BSC \\
\hline 2-year survival rate & $77.2 \%$ & $59.5 \%$ & $16.7 \%$ \\
\hline Median survival time, months & 40.5 & 28.1 & 13.0 \\
\hline
\end{tabular}

CP, Child Pugh; RFA, radiofrequency ablation; TACE, transarterial chemoembolization; HAIC, hepatic arterial infusion chemotherapy; LT, liver transplantation; SOR, sorafenib; BSC, best supportive care.
Table 3. Substaging of the intermediate stage proposed by the Japanese Society of Transcatheter Hepatic Arterial Embolization [24]

This result was not confirmed by a German study carried out on 884 patients [21]. In 2015 , Scaffaro et al. [22] validated this substaging in terms of prognosis regarding 136 intermediate-stage HCC patients treated with transarterial embolization (TAE). In fact, median survival progressively decreased across the substages, being 33.5 months (95\% CI 32.8-34.3) in B1, 28.6 months (95\% CI 27.5-29.8) in B2, 19.0 months (95\% CI 17.2-20.9) in B3, and 13 months in B4 ( $p=0.013)$.

The most recent evaluation of the prognostic capability of the subclassification of Bolondi et al. [16] has been carried out by Kim et al. [23] on 821 patients treated with TACE. The B1, B2 and B3 subclasses showed significantly different survival rates between the contiguous stages with a median survival of 51.5, 26, and 14.8 months, respectively $(p<0.001$ for each comparison with the contiguous stratum until B3); however, the discriminatory ability and the gradient monotonicity of the system disappeared between B3 and B4 since the median survival of B3 was worse than that of B4 patients ( 14.8 vs. 25 months, $p=0.025$ ). The authors suggested a reclassification, adopting the so-called "up-to-11 criteria," instead of up-to-7 criteria (Table 2). According to the new proposal, median survival progressively decreased from B1 (44.8 months) to B2 (21.5 months) and B3 (11.3 months), with a significant difference between the contiguous stages $(p<0.001$ for the comparison of each stage with the subsequent one).

Another proposal, based on the "4-of-7 cm criterion" (no more than 4 tumours, each not exceeding $7 \mathrm{~cm}$ ) and the Child-Pugh score, comes from the Japanese Society of Transcatheter Hepatic Arterial Embolization (JSTHAE) [24] (Table 3). This group demonstrated that a tumour burden meeting the 4-of-7 cm criterion and Child-Pugh class A (scores 5-6) were favourable prognostic factors for intermediate-stage HCC patients. Therefore, they allocated 
Table 4. Subclassification and treatment strategy of intermediate-stage HCC according to the Kinki criteria of the BCLC B substage [27]

\begin{tabular}{|c|c|c|c|c|}
\hline BCLC substage & B1 & B2 & B3 & \\
\hline Child-Pugh score & $5-7$ & $5-7$ & $8-9$ & \\
\hline \multirow{2}{*}{$\begin{array}{l}\text { Beyond Milan and } \\
\text { within up-to-7 }\end{array}$} & in & out & any & \\
\hline & & & in & out \\
\hline Substage & & & B3 A & B3 B \\
\hline $\begin{array}{l}\text { Concept of treatment } \\
\text { strategy }\end{array}$ & curative intent & $\begin{array}{l}\text { non-curative, } \\
\text { palliative }\end{array}$ & $\begin{array}{l}\text { curative intent if } \\
\text { within up-to-7 }\end{array}$ & $\begin{array}{l}\text { palliative, no } \\
\text { treatment }\end{array}$ \\
\hline Treatment option & $\begin{array}{l}\text { resection } \\
\text { ablation } \\
\text { superselective cTACE }\end{array}$ & $\begin{array}{l}\text { DEB-TACE } \\
\text { HAIC }^{2} \\
\text { sorafenib }^{3}\end{array}$ & $\begin{array}{l}\text { transplantation } \\
\text { ablation } \\
\text { superselective cTACE }\end{array}$ & $\begin{array}{l}\text { HAIC } \\
\text { selective } \\
\text { DEB-TACE }\end{array}$ \\
\hline Alternative & $\begin{array}{l}\text { DEB-TACE (large, Child-Pugh } \\
\text { score 7) } \\
\text { B-TACE }^{4}\end{array}$ & cTACE & $\begin{array}{l}\text { DEB-TACE } \\
\text { B-TACE, HAIC }\end{array}$ & $\mathrm{BSC}$ \\
\hline
\end{tabular}

TACE, transarterial chemoembolizatin; DEB-TACE, TACE with drug-eluting beads; cTACE, conventional TACE; BSC, best supportive care. ${ }^{1}$ DEB-TACE is recommended for very large tumours of $>6 \mathrm{~cm} .{ }^{2}$ HAIC (hepatic arterial infusion chemotherapy) is recommended for multiple tumours of $>6 \mathrm{~cm} .{ }^{3}$ Sorafenib is recommended for patients having liver function with a Child-Pugh score of 5 and $6 .{ }^{4}$ B-TACE (balloon-occluded TACE) is recommended when there are fewer tumours.

intermediate-stage patients with these characteristics to the B1 substage. They then generated the B3 substage, which included patients having a Child-Pugh score of 9. The B2 stage encompassed patients other than B1 and B3. The 2-year survival rate and the median survival were $77.2 \%$ and 40.5 months in B1, 59.5\% and 28.1 months in B2 and $16.7 \%$, and 13.0 months in B3, respectively. The discriminatory ability of this system was demonstrated by the significant differences found in survival between the substages (B1 vs. B2: $p<0.0001$; B2 vs. B3: $p=0.0014$ ).

An additional BCLC B subclassification has been developed by Kudo et al. [25, 26] who has proposed the "Kinki criteria" which incorporate the ideas of classifying patients by ChildPugh scores (up-to 7 and 8-9) and the "beyond Milan" and "up-to-7" criteria from the Bolondi et al. classification. The Kinki staging system relies on three substages (Table 4). The "quasi C" substage was not included since Asian guidelines recommend TACE for these patients [27]. The Kinki staging system includes resection and ablation among first-line treatments for B1 patients. Resection is proposed for Child-Pugh score 5 patients with a single but large tumour while ablation may be used in cases of 4-6 small tumours. If the tumour size is close to $5 \mathrm{~cm}$, TACE and ablation could be combined to expand the ablation area. In patients with several nodules, superselective conventional TACE (CTACE) can be considered in order to carefully treat the tumours one by one with curative intent. When superselective catheterization is not applicable, TACE with drug-eluting beads (DEB-TACE) or balloon-occluded TACE [28] may be alternative options.

In patients with substage B2 HCC, which is beyond the up-to-7 criteria, repeated DEB-TACE is proposed when there are only a few lesions being $>6 \mathrm{~cm}$, while in the setting of multiple nodules, hepatic arterial infusion chemotherapy (HAIC) or sorafenib are recommended. Sorafenib may be considered as the first-line treatment for patients who have bilobar multiple 


\section{Liver Cancer}

HCC beyond the up-to- 7 criteria and are expected to easily become refractory to cTACE with a high risk of worsening liver function.

Patients in substage B3 have a liver function so poor that they should be managed with palliative care or no treatment. However, according to the Kinki proposal, in those patients meeting the up-to-7 criteria, it is important to aim for a potential cure with liver transplantation (adopting extended criteria or downstaging) and a survival benefit using superselective DEB-TACE, ablation, or HAIC, which minimally decrease liver function. The authors assessed the prognosis of patients treated with cTACE (either superselective or non-selective procedures) at their institution according to the Kinki criteria and confirmed that overall survival (OS) rates in substages B1, B2 and B3 HCC were well stratified.

Finally, another substaging system has been developed by Ogasawara et al. [29] on a series of 350 intermediate-stage patients treated with TACE, the so-called CHIP score, based on the Child-Pugh score, number of liver tumours, and presence of HCV-RNA. Five subgroups were identified ( $0-2$ points, 3 points, 4 points, 5 points, and 6-7 points) with a median survival time ranging from 65.2 to 8.4 months.

In an attempt to estimate the potential applicability of these subclassifications in clinical practice, it should be noted that two of them $[16,23]$ accept the BCLC position of excluding PS 1 patients from the intermediate stage (with the exception of the Bolondi et al. B4 substage). In the ECOG scale, PS 1 refers to patients not being able to engage in strenuous physical activity but being ambulatory and able to carry out work of a light or sedentary nature, such as light housework or office work. Therefore, PS 1 does not preclude access to any type of HCC treatment and, consequently, the Italian guidelines for the management of HCC patients have not accepted the exclusion of these patients from the BCLC B stage (or its substages) [30]. In line with the Italian position, the two Japanese proposals of BCLC B subclassification do not mention PS 0 among the essential criteria.

In conclusion, movements to subdivide the BCLC intermediate stage are underway because of the marked diversity of patients included in this stage. Before being endorsed by guidelines and followed in clinical practice, substaging systems must be externally validated in terms of prognostic ability and suitability to suggest the most appropriate therapy for each patient, which cannot be limited to TACE or TARE (after TACE failures) but should take into account several other options, such as hepatectomy and ablation, liver transplantation, HAIC, systemic therapy with sorafenib, or BSC, depending on the tumour burden and liver function reserve.

Similar to the intermediate stage, the advanced HCC stage (BCLC stage C), which includes up to $30-35 \%$ of the patients at presentation in countries without nationwide surveillance programs [31-33], consists of a wide variety of patients with one or more adverse predictors, such as symptomatic tumours causing a decline in PS (ECOG PS 1 or 2), macrovascular invasion (MVI), regardless of its location (hepatic veins [HV] or portal radicles) and extension, and extrahepatic spread (EHS), such as lymph node involvement or distant metastases, in patients with a wide range of residual liver function, defined by Child-Pugh class A or B [7]. Despite this heterogeneity, BCLC strategy and AASLD practice guidelines recommend systemic therapy as a unique treatment option for patients with advanced HCC and preserved liver function (Child-Pugh class A) [3, 4, 8, 9, 34]. On the contrary, the Hong Kong Liver Cancer (HKLC) staging system and the Japanese guidelines consider TACE, resection, HAIC, and molecular-targeted agents all as possible treatment alternatives in advanced-stage patients, depending upon patients' clinical conditions and tumour extension [27, 35].

Sorafenib has been proven to significantly prolong the survival of BCLC stage C patients as compared to a placebo in two randomized phase 3 trials, and its efficacy has been confirmed in post-marketing studies [34, 36-41]. Post hoc analyses of registration trials have confirmed the utility of this treatment in several patient subclasses, including those with MVI and/or EHS, or poor PS, although these features adversely affect survival [37-39]. Moreover, the 
Golfieri et al.: Patients with Barcelona Clinic Liver Cancer Stages B and C Hepatocellular Carcinoma: Time for a Subclassification

latest BCLC update has acknowledged the positive results of recent randomized trials, introducing lenvatinib in first line, which has been proven to be non-inferior to sorafenib, and regorafenib in second line, which has been shown to improve survival compared to placebo in selected patients progressing after sorafenib $[4,42,43]$.

It is important to point out that, in the majority of cases, MVI occurs in the portal system; it may involve only the segmental or sectoral branches, or it can extend to the left or right main portal vein, or to the main trunk and beyond. These different types of tumoural portal vein thrombosis (PVT) cannot be considered prognostically equivalent since they have a different disease course [40]. A recent retrospective study [41] reports that the median survival of HCC patients with PVT treated with sorafenib as monotherapy was only 3.9 months in the case of involvement of the main trunk and 8.1 months when the first branch was invaded. Therefore, the extent of PVT should be assessed and staged differently.

The high heterogeneity of BCLC stage C patients has prompted expert centres to select some patients for alternative treatments. In particular, resection [44, 45], TACE [12, 46], radiotherapy, HAIC [47], TARE [48], systemic cytotoxic chemotherapy [49], TACE plus sorafenib [50], sorafenib plus radiotherapy [51], and liver transplantation after the combined use of locoregional therapy [52] have been employed on an empirical basis in the actual practice. The following are therapeutic alternatives to sorafenib (median survival recorded after resection 27.8 months) [44] for BCLC stage C patients: DEB-TACE (13.5 months) [46] or TARE (13.0 months) [53]; the median survival is longer than that obtained with sorafenib in the Sorafenib Hepatocellular Carcinoma Assessment Randomized Protocol (SHARP) study (10.7 months) [54] and in the Asia-Pacific study (6.5 months) [55].

The recently updated Asia-Pacific clinical practice guidelines underline that the sole presence of MVI does not represent a sufficient criterion to consider the patient unsuitable for potentially curative treatments, such as resection, or locoregional approaches, such as TACE [27].

In 2010, Shi et al. [45] classified PVT into 4 categories for surgical purposes: (1) tumour thrombi involving only sectoral or segmental portal branches; (2) involvement of the right/ left portal vein; (3) involvement of the main portal trunk; and (4) involvement of the main portal trunk up to the superior mesenteric vein. The same authors reported differences in survival based on the portal vein invasion patterns cited. This result was in line with a previous study by Park et al. [40] who, in a series of 904 HCC patients, showed that both the presence and the extent of PVT (no portal vein invasion, 1st and 2nd branch invasion, and main portal vein invasion) were independent predictors of survival.

Considering the different clinical outcomes based on the extent of PVT [30, 32, 56], in the proposed subclassification of intermediate-stage HCC, Bolondi et al. [16] introduced a substage beyond B4, called "quasi C," which represents a sort of overlap between the intermediate and the advanced stages (Table 1). This stage includes Child-Pugh class A, PS 0 patients with peripheral (subsegmental or segmental) PVT for whom TACE or TARE could also be considered as alternative treatment options to sorafenib.

MVI can also involve the HV, extending into the inferior vena cava and leading to the formation of thrombi in the right atrium, lung metastasis and pulmonary embolism. Although less frequent, the involvement of the HV seems to be associated with poorer prognosis compared to PVT. However, as for PVT, several treatments have been proposed in selected patients, including TACE, TARE, and resection $[19,53,57,58]$. In a recent nationwide survey on Child-Pugh class A patients with HV thrombosis not extending into the inferior vena cava, Kokudo et al. [59] reported a significantly longer median survival (4.47 years) in resected patients compared to nonresected patients $(1.58$ years, $p<0.001)$ and significantly longer survival in patients without PVT (median 5.67 years) compared to patients with PVT (1.88 years, $p<0.001$ ). 


\section{Liver

Golfieri et al.: Patients with Barcelona Clinic Liver Cancer Stages B and C Hepatocellular Carcinoma: Time for a Subclassification

Another independent determinant of survival was the type of EHS. In the American Joint Committee on Cancer/Union for International Cancer Control Tumor-Node-Metastasis (AJCC/ UICC TNM) 7th staging system, regional lymph node metastasis (N1) and distant metastasis (M1) are classified separately, while the BCLC staging system does not differentiate between these two conditions. Although it is difficult to assess the effect of EHS on survival, since the majority of these patients die from intrahepatic progression of HCC [60], there is evidence which indicates that nodal and distant metastasis should not be merged, as their survival varies [61]. In the study by Hasegawa et al. [62], patients with pathologically proven regional lymph node invasion (any T, N1, M0) had a survival rate similar to that in patients with advanced T stage (T4, N0, M0), while those with distant metastases (any T, any N, M1) had a significantly shorter survival.

Based on the actual clinical need for a more precise categorization of BCLC C patients, several proposals of subclassification have recently been published. The first suggestion came in 2015 from Sinn et al. [63] who demonstrated a better prediction of survival when BCLC stage $C$ was substaged according to the extent of PVT and the type of EHS. In their retrospective study on 582 treatment-naïve patients, the extent of the PVT was divided into 4 classes: none, type I - segmental/sectoral branches, type II - left and/or right portal vein, and type III - main portal vein trunk. The type of EHS was divided into nodal and distant metastases. They demonstrated that the median survival was significantly different between $\mathrm{C} 1$ (PVT-0/I without distant EHS), C2 (PVT-II/III without distant EHS), C3 (PVT-0/I with distant EHS), and C4 (PVT-II/III with distant EHS) (11.7, 5.7, 4.9, and 2.3 months, respectively).

Another proposal came in 2017 from Jun et al. [64] who retrospectively analysed 196 consecutive BCLC stage C HCC patients aiming to assess the heterogeneity of these cases and to suggest individualized treatment strategies as an alternative to sorafenib. In multivariate Cox regression analyses, tumour size, distant metastasis, HCC type, and bile duct invasion were significantly associated with 1-, 3-, and 5-year survival rates. Therefore, these 4 characteristics were used to subclassify BCLC stage $\mathrm{C}$ into 5 substages ( $\mathrm{C} 0-\mathrm{C} 4)$, based on the number $(0-4)$ of characteristics which were present. This subclassification showed significant associations with survival, and with median survival times of 3,026, 605, 224, 126, and 82 days for patients with stages $\mathrm{C} 0, \mathrm{C} 1, \mathrm{C} 2, \mathrm{C} 3$, and C4, respectively $(p<0.001)$. The reliability of this subclassification is limited by the low sample size, particularly at the two edges of this staging system.

More recently, Giannini et al. [56], by analysing the largest Italian database on HCC (I.T.A.L.I.C.A.), reported that, in clinical practice, BCLC stage C patients are managed in different ways according to these clinical characteristics on the basis of ECOG PS, MVI, and EHS. They identified 5 subclasses (PS 1: patients with PS 1 alone, without MVI or EHS; PS 2: patients with PS 2 alone, without MVI or EHS; MVI: patients with MVI and without EHS, regardless of PS; EHS: patients with EHS and without MVI, regardless of PS; and MVI+EHS: patients with both MVI and EHS, regardless of PS), and demonstrated different treatment distributions (including curative and transarterial therapies, sorafenib, and BSC) and different outcomes in each class. The most frequent treatments were: curative approaches for PS 1 patients (39.7\%), sorafenib for MVI (39.3\%) and EHS patients (37.3\%), and BSC for PS 2 $(41.8 \%)$ and MVI+EHS (51.7\%) patients. Median OS significantly declined from PS 1 (38.6 months) to PS 2 (22.3 months), EHS (11.2 months), MVI (8.2 months), and MVI+EHS (3.1 months) ( $p<0.001)$. Among the MVI patients, OS was longer in those with peripheral MVI (11.2 months) as compared to patients with central (portal trunk) MVI (7.1 months, $p=$ 0.005). A different life expectancy among subclasses was observed even among patients treated only with BSC. These results provided clear evidence that BCLC stage C patients may have a very different "natural history," and that they are currently managed with a wide range of therapies which are dictated by their clinical profile. 


\section{Liver Cancer}

Selective TARE has been proposed as a valid alternative for the treatment of HCC with type I or II PVT, with response rates and OS rates similar to those obtained in the treatment of HCC without PVT $[19,53,65]$. In the first large European series which included 325 patients treated with TARE, Sangro et al. [19] reported a median OS of 10.7 months in branch PVT, not significantly different from that of patients without PVT (15.3 months). The extent of the PVT was associated with survival in the phase 2 study by Mazzaferro et al. [53], who reported a median OS of 16 months in 23 patients with type I or II PVT, very similar to the 18 months of OS gained in 17 patients without PVT. Similar data were reported by Golfieri et al. [65] in 104 patients with HCC treated with TARE. The median OS was 17 months in patients with segmental PVT, which was equal to that of patients without PVT, but significantly longer as compared to patients with right/left branch and lobar PVT (6.4 and 5.4 months, respectively).

In the setting of peripheral PVT, even TACE can be effective, although, in the current AASLD guidelines, the presence of any type of MVI is considered to be the main contraindication for TACE [8]. Conversely, many Oriental clinicians consider TACE as a possible treatment for patients with unresectable HCC and PVT $[12,30]$. Two studies have demonstrated that TACE could be performed safely in these patients [66, 67].

Pertinent to this issue are the results of a retrospective study which compared the efficacy of TACE and sorafenib in advanced-stage HCC patients (35\% of patients treated with TACE had PVT). No significant difference was found between these two treatments in terms of OS (9.2 vs. 7.4 months) [68].

The superiority of TACE over BSC is confirmed by a meta-analysis including 8 comparative studies ( 3 prospective and 5 retrospective studies) involving 1,601 HCC patients [69]. Transarterial chemoembolization significantly improved the 6-month and 1-year OS of patients with PVT as compared to conservative treatment. Moreover, subgroup analyses showed that TACE was effective in HCC patients with either main trunk or segmental PVT. Because of the various inclusion criteria, survival greatly varied in these studies, ranging from 5 to 8.7 months.

However, no solid data are currently available comparing TACE with sorafenib in patients with PVT and a clear definition of prognostic factors affecting the survival of these patients after TACE is lacking.

The survival figures of TACE in patients with PVT are reported by the systematic review of Zhao [70]. In all the papers reviewed, the median OS of Child-Pugh class A patients was significantly longer in cases of peripheral (types I/II) PVT, ranging from 19 to 10.2 months, than in cases of central/main trunk invasion (types III/ IV), ranging from 7 to 5.3 months. Furthermore, this review claimed that a clear distinction of the PVT extent should be considered for a subclassification of these patients and to correspondingly redirect them to the most effective treatment.

HAIC is not recommended as the standard of care in the major guidelines, even in the updated versions [9, 71], except for Japanese guidelines [27]. While its adoption is limited in Western countries, HAIC has become widely used in Asia, especially Japan. A Japanese nationwide survey demonstrated survival benefits in advanced patients who received HAIC ( $n=341$, median survival 14.0 months) compared to patients who did not receive active treatment ( $n=341,5.2$ months) (hazard ratio, $0.60 ; 95 \%$ CI, $0.49-0.73 ; p<0.0001)$ [72]. The benefit was maintained in patients with PVT thrombus.

Currently, there are no established criteria used for the selection of advanced HCC patients to receive either sorafenib or HAIC. In a small retrospective series, Moriguchi et al. [73] reported significantly longer survival in patients with tumour thrombus involving the main trunk and the first branches of the portal vein (types III and IV) treated with HAIC, compared to sorafenib, suggesting the use of HAIC is first-line in these patients, followed by sorafenib in case of no response. 


\section{Liver Cancer}

HAIC could also represent a safe treatment option in selected Child-Pugh class B patients, who are contraindicated to sorafenib [74, 75]. Ikeda et al. [75] prospectively evaluated 108 patients in a multicentre phase II trial in chemo-naïve patients with advanced HCC with ChildPugh scores of 5-7. The patients were randomized to receive sorafenib alone $(n=42)$ or sorafenib combined with HAIC with cisplatin $(n=66)$. The combination HAIC plus sorafenib yielded favourable OS when compared with sorafenib (median survival of $10.6 \mathrm{vs} .8 .7$ months). However, the median time to progression and the response rate were similar, i.e., 2.8 months and $7.3 \%$ in the sorafenib arm and 3.1 months and $21.7 \%$ in the combination arm, respectively [75]. In a retrospective analysis on 179 Child-Pugh class B patients treated with HAIC, Terashima et al. [76] reported an improvement of liver function in patients with Child-Pugh scores of 7 and 8 who responded to HAIC, with a median OS of 12.1 and 11.9 months, respectively. On the contrary, no advantages were demonstrated for patients with a Child-Pugh score of 9.

A more recent phase III trial (SILIUS) tested the combination of sorafenib with continuous HAIC with cisplatin and fluorouracil, via an implanted catheter system, against sorafenib monotherapy in patients with advanced, unresectable HCC [77]. Their results failed to demonstrate a significant improvement of OS in the addition of HAIC to sorafenib.

Therefore, some treatment strategies can be proposed, at least for patients with PVT, based on the literature:

- The presence of PS 1 can no longer be accepted as sufficient for allocating patients to the advanced stage since it inhibits any potential treatment for HCC.

- The extent of MVI is an important determinant of prognosis and can drive the treatment choice which may range from surgical resection to systemic therapies (including TARE, TACE, and TAE). In fact, surgery and TACE/TAE/TARE have no technical contraindications in the presence of PVT when this is limited, at most, to a subsegmental or segmental branch in Child-Pugh class A patients whereas only TARE should be utilized in the presence of lobar branch involvement.

- In cases of main portal trunk PVT, patients should be properly classified as BCLC stage C and treated accordingly, provided that they belong to Child-Pugh class A.

- In selected Child-Pugh class B patients, HAIC could represent a safe and effective treatment, although BSC is frequently the only possible option.

In conclusion, subclassifications of intermediate and advanced BCLC stages are urgently needed and require extensive validation in order to guide clinicians towards the most effective treatment option. The analysis of the data available on large registries [13, 32, 56, 59, 62, 72] could represent the basis to identify prognostic factors enabling patients' stratification in the different stages. Indeed, the failure of some of the largest recent randomized studies [78, 79] demonstrates that there cannot be scientific development when trials are conducted in a generalized, unselected population. Thus, these subclassifications should represent the next step to build the basis for future research and randomized controlled trials involving intermediate- to advanced-stage HCC patients.

\section{Disclosure Statement}

The authors declare no conflicts of interest. 


\section{References}

1 Llovet JM, Bru C, Bruix J: Prognosis of hepatocellular carcinoma: the BCLC staging classification. Semin Liver Dis 1999;19:329-338.

2 Forner A, Reig ME, de Lope CR, Bruix J: Current strategy for staging and treatment: the BCLC update and future prospects. Semin Liver Dis 2010;30:61-74.

3 Forner A, Llovet JM, Bruix J: Hepatocellular carcinoma. Lancet 2012;379:1245-1255.

4 Forner A, Reig M, Bruix J: Hepatocellular carcinoma. Lancet 2018;391:1301-1314.

5 Marrero JA, Fontana RJ, Barrat A, Askari F, Conjeevaram HS, Su GL, Lok AS: Prognosis of hepatocellular carcinoma: comparison of 7 staging systems in an American cohort. Hepatology 2005;41:707-716.

6 Cillo U, Vitale A, Grigoletto F, Farinati F, Brolese A, Zanus G, Neri D, Boccagni P, Srsen N, D’Amico F, Ciarleglio FA, Bridda A, D’Amico DF: Prospective validation of the Barcelona Clinic Liver Cancer staging system. J Hepatol 2006;44:723-731.

7 Guglielmi A, Ruzzenente A, Pachera S, Valdegamberi A, Sandri M, D’Onofrio M, Iacono C: Comparison of seven staging systems in cirrhotic patients with hepatocellular carcinoma in a cohort of patients who underwent radiofrequency ablation with complete response. Am J Gastroenterol 2008;103:597-604.

8 Bruix J, Sherman M; American Association for the Study of Liver Diseases: Management of hepatocellular carcinoma: an update. Hepatology 2011;53:1020-1022.

9 European Association for the Study of The Liver - EASL Clinical Practice Guidelines: Management of hepatocellular carcinoma. J Hepatol 2018, Epub ahead of print.

10 Piscaglia F, Bolondi L: The intermediate hepatocellular carcinoma stage: should treatment be expanded? Dig Liver Dis 2010;42:S258-S263.

11 Raoul JL, Sangro B, Forner A, Mazzaferro V, Piscaglia F, Bolondi L, Lencioni R: Evolving strategies for the management of intermediate-stage hepatocellular carcinoma: available evidence and expert opinion on the use of transarterial chemoembolization. Cancer Treat Rev 2011;37:212-220.

12 Piscaglia FA, Ogasawara SB: Patient selection for transarterial chemoembolization in hepatocellular carcinoma: importance of benefit/risk assessment. Liver Cancer 2018;7:104-119.

13 Giannini EG, Moscatelli A, Pellegatta G Vitale A, Farinati F, Ciccarese F, Piscaglia F, Rapaccini GL, Di Marco M, Caturelli E, Zoli M, Borzio F, Cabibbo G, Felder M, Sacco R, Morisco F, Missale G, Foschi FG, Gasbarrini A, Baroni GS, Virdone R, Masotto A, Trevisani F; Italian Liver Cancer (ITA.LI.CA) Group: Application of the intermediate-stage subclassification to patients with untreated hepatocellular carcinoma. Am J Gastroenterol 2016;111:70-77.

14 Bruix J, Reig M, Sherman M: Evidence-based diagnosis, staging, and treatment of patients with hepatocellular carcinoma. Gastroenterology 2016;150:835-853.

15 Kadalayil L, Benini R, Pallan L, O’Beirne J, Marelli L, Yu D, Hackshaw A, Fox R, Johnson P, Burroughs AK, Palmer DH, Meyer T: A simple prognostic scoring system for patients receiving transarterial embolisation for hepatocellular cancer. Ann Oncol 2013;24:2565-2570.

16 Bolondi L, Burroughs A, Dufour JF, Galle PR, Mazzaferro V, Piscaglia F, Raoul JL, Sangro B: Heterogeneity of patients with intermediate (BCLC B) Hepatocellular Carcinoma: proposal for a subclassification to facilitate treatment decisions. Semin Liver Dis 2012;32:348-359.

17 Mazzaferro V, Llovet JM, Miceli R, Bhoori S, Schiavo M, Mariani L, Camerini T, Roayaie S, Schwartz ME, Grazi GL, Adam R, Neuhaus P, Salizzoni M, Bruix J, Forner A, De Carlis L, Cillo U, Burroughs AK, Troisi R, Rossi M, Gerunda GE, Lerut J, Belghiti J, Boin I, Gugenheim J, Rochling F, Van Hoek B, Majno P; Metroticket Investigator Study Group: Predicting survival after liver transplantation in patients with hepatocellular carcinoma beyond the Milan criteria: a retrospective, exploratory analysis. Lancet Oncol 2009;10:35-43.

18 Salem R, Lewandowski RJ, Mulcahy MF, Riaz A, Ryu RK, Ibrahim S, Atassi B, Baker T, Gates V, Miller FH, Sato KT, Wang E, Gupta R, Benson AB, Newman SB, Omary RA, Abecassis M, Kulik L: Radioembolisation for hepatocellular carcinoma using Yttrium-90 microspheres: a comprehensive report of long-term outcomes. Gastroenterology 2010;138:52-64.

19 Sangro B, Carpanese L, Cianni R, Golfieri R, Gasparini D, Ezziddin S, Paprottka PM, Fiore F, Van Buskirk M, Bilbao JI, Ettorre GM, Salvatori R, Giampalma E, Geatti O, Wilhelm K, Hoffmann RT, Izzo F, Iñarrairaegui M, Maini CL, Urigo C, Cappelli A, Vit A, Ahmadzadehfar H, Jakobs TF, Lastoria S; European Network on Radioembolisation with Yttrium-90 Resin Microspheres (ENRY): Survival after yttrium-90 resin microsphere radioembolisation of hepatocellular carcinoma across Barcelona clinic liver cancer stages: a European evaluation. Hepatology 2011;54:868-878.

20 Ha Y, Shim JH, Kim SO, Kim KM, Lim YS, Lee HC: Clinical appraisal of the recently proposed Barcelona Clinic Liver Cancer Stage B subclassification by survival analysis. J Gastroenterol Hepatol 2014;29:787-793.

21 Weinmann A, Koch S, Sprinzl M, Kloeckner R, Schulze-Bergkamen H, Düber C, Lang H, Otto G, Wörns MA, Galle PR: Survival analysis of proposed BCLC-B subgroups in hepatocellular carcinoma patients. Liver Int 2015;35: 591-600.

22 Scaffaro LA, Stella SF, Alvares-Da-Silva MR, Kruel CD: Survival rates according to Barcelona clinic liver cancer sub-staging system after transarterial embolisation for intermediate hepatocellular carcinoma. World J Hepatol 2015;7:628-632.

23 Kim JH, Shim JH, Lee HC, Sung KB, Ko HK, Ko GY, Gwon DI, Kim JW, Lim YS, Park SH: New intermediate-stage subclassification for patients with hepatocellular carcinoma treated with transarterial chemoembolization. Liver Int 2017;37:1861-1868. 
Golfieri et al.: Patients with Barcelona Clinic Liver Cancer Stages B and C Hepatocellular Carcinoma: Time for a Subclassification

24 Yamakado K, Miyayama S, Hirota S, Mizunuma K, Nakamura K, Inaba Y, Yamamoto S, Matsuo K, Nishida N, Aramaki T, Anai H, Kora S, Oikawa S, Watanabe K, Yasumoto T, Furuichi K, Yamaguchi M: Prognosis of patients with intermediate-stage hepatocellular carcinomas based on the Child-Pugh score: subclassifying the intermediate stage (Barcelona Clinic Liver Cancer stage B). Jpn J Radiol 2014;32:644-649.

25 Kudo M, Arizumi T, Ueshima K, Sakurai T, Kitano M, Nishida N: Subclassification of BCLC B stage hepatocellular carcinoma and treatment strategies: proposal of modified Bolondi's subclassification (Kinki criteria). Dig Dis 2015;33:751-758.

26 Kudo M: Heterogeneity and subclassification of Barcelona Clinic Liver Cancer Stage B. Liver Cancer 2016;5: 91-96.

27 Omata O, Cheng A, Kokudo N, Kudo M, Lee JM, Jia J, Tateishi R, Han K, Chawla YK, Shiina S, Jafri W, Payawal DA, Ohki T, Ogasawara S, Chen P, Lesmana CRA, Lesmana LA, Gani RA, Obi S, Dokmeci AK, Sarin SK: Asia-Pacific clinical practice guidelines on the management of hepatocellular carcinoma: a 2017 update. Hepatol Int 2017; 11:317-370.

28 Irie T, Kuramochi M, Takahashi N: Dense accumulation of lipiodol emulsion in hepatocellular carcinoma nodule during selective balloon-occluded transarterial chemoembolisation: measurement of balloon-occluded arterial stump pressure. Cardiovasc Intervent Radiol 2013;36:706-713.

29 Ogasawara S, Chiba T, Ooka Y, Kanogawa N, Motoyama T, Suzuki E, Tawada A, Azemoto R, Shinozaki M, Yoshikawa M, Yokosuka O: A prognostic score for patients with intermediate-stage hepatocellular carcinoma treated with transarterial chemoembolization. PLoS One 2015;10:e0125244.

30 Italian Association for the Study of the Liver (AISF); AISF Expert Panel; AISF Coordinating Committee, Bolondi L, Cillo U, Colombo M, Craxì A, Farinati F, Giannini EG, Golfieri R, Levrero M, Pinna AD, Piscaglia F, Raimondo G, Trevisani F, Bruno R, Caraceni P, Ciancio A, Coco B, Fraquelli M, Rendina M, Squadrito G, Toniutto P: Position paper of the Italian Association for the Study of the Liver (AISF): The multidisciplinary clinical approach to hepatocellular carcinoma. Dig Liver Dis 2013;45:712-723.

31 Villanueva A, Hernandez-Gea V, Llovet JM: Medical therapies for hepatocellular carcinoma: a critical view of the evidence. Nat Rev Gastroenterol Hepatol 2013;10:34-42.

32 Bucci L, Garuti F, Lenzi B, Pecorelli A, Farinati F, Giannini EG, Granito A, Ciccarese F, Rapaccini GL, Di Marco M, Caturelli E, Zoli M, Borzio F, Sacco R, Cammà C, Virdone R, Marra F, Felder M, Morisco F, Benvegnù L, Gasbarrini A, Svegliati-Baroni G, Foschi FG, Missale G, Masotto A, Nardone G, Colecchia A, Bernardi M, Trevisani F; Italian Liver Cancer (ITA.LI.CA) group: The evolutionary scenario of hepatocellular carcinoma in Italy: an update. Liver Int 2017;37:259-270.

33 Mittal S, Kanwal F, Ying J, Chung R, Sada YH, Temple S, Davila JA, El-Serag HB: Effectiveness of surveillance for hepatocellular carcinoma in clinical practice: a United States cohort. J Hepatol 2016;65:1148-1154.

34 Cheng AL, Kang YK, Chen Z, Tsao CJ, Qin S, Kim JS, Luo R, Feng J, Ye S, Yang TS, Xu J, Sun Y, Liang H, Liu J, Wang J, Tak WY, Pan H, Burock K, Zou J, Voliotis D, Guan Z: Efficacy and safety of sorafenib in patients in the AsiaPacific region with advanced hepatocellular carcinoma: a phase III randomised, double-blind, placebocontrolled trial. Lancet Oncol 2009;10:25-34.

35 Yau T, Tang VYF, Yao T, Fan S, Lo C, Poon RTP: Development of Hong Kong liver cancer staging system with treatment stratification for patients with hepatocellular carcinoma. Gastroenterology 2014;146:1691-1700.

36 Llovet JM, Ricci S, Mazzaferro V, Hilgard P, Gane E, Blanc JF, de Oliveira AC, Santoro A, Raoul JL, Forner A, Schwartz M, Porta C, Zeuzem S, Bolondi L, Greten TF, Galle PR, Seitz JF, Borbath I, Häussinger D, Giannaris T, Shan M, Moscovici M, Voliotis D, Bruix J; SHARP Investigators Study Group: Sorafenib in advanced hepatocellular carcinoma. N Engl J Med 2008;359:378-390.

37 Iavarone M, Cabibbo G, Piscaglia F, Zavaglia C, Grieco A, Villa E, Cammà C, Colombo M; SOFIA (SOraFenib Italian Assessment) study group: Field-practice study of sorafenib therapy for hepatocellular carcinoma: a prospective multicenter study in Italy. Hepatology 2011;54:2055-2063.

38 Daniele B, Croitoru A, Papandreou C, Bronowicki JP, Mathurin P, Serejo F, Stål P, Turnes J, Ratziu V, Bodoky G: Impact of sorafenib dosing on outcome from the European patient subset of the GIDEON study. Future Oncol 2015;11:2553-2562.

39 Bruix J, Raoul JC, Sherman M, Mazzaferro V, Bolondi L, Craxi A, Galle PR, Santoro A, Beaugrand M, Sangiovanni A, Porta C, Gerken G, Marrero JA, Nadel A, Shan M, Moscovici M, Voliotis D, Llovet JM: Efficacy and safety of sorafenib in patients with advanced hepatocellular carcinoma: subanalyses of a phase III trial. J Hepatol 2012; 57:821-829.

40 Park KW, Park JW, Choi JI, Kim TH, Kim SH, Park HS, Lee WJ, Park SJ, Hong EK, Kim CM: Survival analysis of 904 patients with hepatocellular carcinoma in a hepatitis B virus-endemic area. J Gastroenterol Hepatol 2008; 23:467-473.

41 Kuo YH, Wu IP, Wang JH, Hung CH, Rau KM, Chen CH, Kee KM, Hu TH, Lu SN: The outcome of sorafenib monotherapy on hepatocellular carcinoma with portal vein tumour thrombosis. Invest New Drugs 2018;36:307314.

42 Bruix J, Qin S, Merle P, Granito A, Huang YH, Bodoky G, Pracht M, Yokosuka O, Rosmorduc O, Breder V, Gerolami R, Masi G, Ross PJ, Song T, Bronowicki JP, Ollivier-Hourmand I, Kudo M, Cheng AL, Llovet JM, Finn RS, LeBerre MA, Baumhauer A, Meinhardt G, Han G; RESORCE Investigators: Regorafenib for patients with hepatocellular carcinoma who progressed on sorafenib treatment (RESORCE): a randomised, double-blind, placebocontrolled, phase 3 trial. Lancet 2017;389:56-66. 
43 Kudo M, Finn RS, Qin S, Han KH, Ikeda K, Piscaglia F, Baron A, Park JW, Han G, Jassem J, Blanc JF, Vogel A, Komov D, Evans TRJ, Lopez C, Dutcus C, Guo M, Saito K, Kraljevic S, Tamai T, Ren M, Cheng AL: Lenvatinib versus sorafenib in first-line treatment of patients with unresectable hepatocellular carcinoma: a randomised phase 3 non-inferiority trial. Lancet 2018;391:1163-1173.

44 Yang T, Lin C, Zhai J, Shi S, Zhu M, Zhu N, Lu JH, Yang GS, Wu MC: Surgical resection for advanced hepatocellular carcinoma according to Barcelona Clinic Liver Cancer (BCLC) staging. J Cancer Res Clin Oncol 2012;138: 1121-1129.

45 Shi J, Lai EC, Li N, Guo WX, Xue J, Lau WY, Wu MC, Cheng SQ: Surgical treatment of hepatocellular carcinoma with portal vein tumour thrombus. Ann Surg Oncol 2010;17:2073-2080.

46 Prajapati HJ, Dhanasekaran R, El-Rayes BF, Kauh JS, Maithel SK, Chen Z, Kim HS: Safety and efficacy of doxorubicin drug-eluting bead transarterial chemoembolization in patients with advanced hepatocellular carcinoma. J Vasc Interv Radiol 2013;24:307-315.

47 Park JY, Ahn SH, Yoon YJ, Kim JK, Lee HW, Lee DY, Chon CY, Moon YM, Han KH: Repetitive short-course hepatic arterial infusion chemotherapy with high-dose 5-fluorouracil and cisplatin in patients with advanced hepatocellular carcinoma. Cancer 2007;110:129-137.

48 Memon K, Kulik L, Lewandowski RJ, Mulcahy MF, Benson AB, Ganger D, Riaz A, Gupta R, Vouche M, Gates VL, Miller FH, Omary RA, Salem R: Radioembolisation for hepatocellular carcinoma with portal vein thrombosis: impact of liver function on systemic treatment options at disease progression. J Hepatol 2013;58:73-80.

49 Yoon E, Yeon JE, Lee HJ, Suh SJ, Lee SJ, Kang SH, Kang K, Yoo YJ, Kim JH, Yim HJ, Byun KS: Systemic cytotoxic chemotherapy of patients with advanced hepatocellular carcinoma in the era of sorafenib nonavailability. J Clin Gastroenterol 2014;48:e22-e29.

50 Choi GH, Shim JH, Kim MJ, Ryu MH, Ryoo BY, Kang YK, Shin YM, Kim KM, Lim YS, Lee HC: Sorafenib alone versus sorafenib combined with transarterial chemoembolization for advanced-stage hepatocellular carcinoma: results of propensity score analyses. Radiology 2013;269:603-611.

51 Cha J, Seong J, Lee IJ, Kim JW, Han KH: Feasibility of sorafenib combined with local radiotherapy in advanced hepatocellular carcinoma. Yonsei Med J 2013;54:1178-1185.

52 Yoo EJ, Shin HS, Kim SU, Joo DJ, Park JY, Choi GH, Kim DY, Ahn SH, Seong J, Koh MJ, Han KH, Chon CY: Orthotopic liver transplantation after the combined use of locoregional therapy and sorafenib for advanced hepatocellular carcinoma. Onco Targets Ther 2013;6:755-759.

53 Mazzaferro V, Sposito C, Bhoori S, Romito R, Chiesa C, Morosi C, Maccauro M, Marchianò A, Bongini M, Lanocita R, Civelli E, Bombardieri E, Camerini T, Spreafico C: Yttrium-90 radioembolisation for intermediate-advanced hepatocellular carcinoma: a phase 2 study. Hepatology 2013;57:1826-1837.

54 Llovet JM, Ricci S, Mazzaferro V, Hilgard P, Gane E, Blanc JF, de Oliveira AC, Santoro A, Raoul JL, Forner A, Schwartz M, Porta C, Zeuzem S, Bolondi L, Greten TF, Galle PR, Seitz JF, Borbath I, Häussinger D, Giannaris T, Shan M, Moscovici M, Voliotis D, Bruix J; SHARP Investigators Study Group: Sorafenib in advanced hepatocellular carcinoma. N Engl J Med 2008;359:378-390.

55 Cheng AL, Kang YK, Chen Z, Tsao CJ, Qin S, Kim JS, Luo R, Feng J, Ye S, Yang TS, Xu J, Sun Y, Liang H, Liu J, Wang J, Tak WY, Pan H, Burock K, Zou J, Voliotis D, Guan Z: Efficacy and safety of sorafenib in patients in the AsiaPacific region with advanced hepatocellular carcinoma: a phase III randomised, doubleblind, placebocontrolled trial. Lancet Oncol 2009;10:25-34.

56 Giannini EG, Bucci L, Garuti F Brunacci M, Lenzi B, Valente M, Caturelli E, Cabibbo G, Piscaglia F, Virdone R, Felder M, Ciccarese F, Foschi FG, Sacco R, Baroni GS, Farinati F, Rapaccini GL, Olivani A, Gasbarrini A, Di Marco M, Morisco F, Zoli M, Masotto A, Borzio F, Benvegnù L, Marra F, Colecchia A, Nardone G, Bernardi M, Trevisani F; Italian Liver Cancer (ITA.LI.CA) group: Patients with advanced hepatocellular carcinoma need a personalized management: a lesson from clinical practice. Hepatology 2018;67:1784-1796.

57 Zhang YF, Wei W, Guo ZX, Wang JH, Shi M, Guo RP: Hepatic resection versus transcatheter arterial chemoembolization for the treatment of hepatocellular carcinoma with hepatic vein tumor thrombus. Jpn J Clin Oncol 2015;45:837-844.

58 Kokudo T, Hasegawa K, Yamamoto S, Shindoh J, Takemura N, Aoki T, Sakamoto Y, Makuuchi M, Sugawara Y, Kokudo N: Surgical treatment of hepatocellular carcinoma associated with hepatic vein tumor thrombosis. J Hepatol 2014;61:583-588.

59 Kokudo T, Hasegawa K, Matsuyama Y, Takayama T, Izumi N, Kadoya M, Kudo M, Kubo S, Sakamoto M, Nakashima O, Kumada T, Kokudo N; Liver Cancer Study Group of Japan: Liver resection for hepatocellular carcinoma associated with hepatic vein invasion: a Japanese nationwide survey. Hepatology 2017;66:510551.

60 Lee HS: Management of patients with hepatocellular carcinoma and extrahepatic metastasis. Dig Dis 2011;29: 333-338.

61 Kee KM, Wang JH, Lin CY, Wang CC, Cheng YF, Lu SN: Validation of the 7th edition TNM staging system for hepatocellular carcinoma: an analysis of 8,828 patients in a single medical center. Dig Dis Sci 2013;58:27212728.

62 Hasegawa K, Makuuchi M, Kokudo N, Izumi N, Ichida T, Kudo M, Ku Y, Sakamoto M, Nakashima O, Matsui O, Matsuyama Y; Liver Cancer Study Group of Japan: Impact of histologically confirmed lymph node metastases on patient survival after surgical resection for hepatocellular carcinoma: report of a Japanese nationwide survey. Ann Surg 2014;259:166-170. 
Golfieri et al.: Patients with Barcelona Clinic Liver Cancer Stages B and C Hepatocellular Carcinoma: Time for a Subclassification

63 Sinn DH, Cho JY, Gwak GY, Paik YH, Choi MS, Lee JH, Koh KC, Paik SW, Yoo BC: Different survival of Barcelona clinic liver cancer stage $\mathrm{C}$ hepatocellular carcinoma patients by the extent of portal vein invasion and the type of extrahepatic spread. PLoS One 2015;10:e0124434.

64 Jun CH, Yoon JH, Cho E, Shin SS, Cho SB, Kim HJ, Park CH, Kim HS, Choi SK, Rew JS: Barcelona clinic liver cancerstage $\mathrm{C}$ hepatocellular carcinoma. A novel approach to subclassification and treatment. Medicine (Baltimore) 2017;96:e6745.

65 Golfieri R, Mosconi C, Cappelli A, Giampalma E, Galaverni MC, Pettinato C, Renzulli M, Monari F, Angelelli B, Pini P, Terzi E, Ascanio S, Garzillo G, Piscaglia F, Bolondi L, Trevisani F: Efficacy of radioembolization according to tumour morphology and portal vein thrombosis in intermediate-advanced hepatocellular carcinoma. Future Oncol 2015;11:3133-3142.

66 Georgiades CS, Hong K, D'Angelo M, Geschwind JF: Safety and efficacy of transarterial chemoembolization in patients with unresectable hepatocellular carcinoma and portal vein thrombosis. J Vasc Interv Radiol 2005; $16: 1653-1659$

67 Lee HS, Kim JS, Choi IJ, Chung JW, Park JH, Kim CY: The safety and efficacy of transcatheter arterial chemoembolization in the treatment of patients with hepatocellular carcinoma and main portal vein obstruction. A prospective controlled study. Cancer 1997;79:2087-2094.

68 Pinter M, Hucke F, Graziadei I, Vogel W, Maieron A, Königsberg R, Stauber R, Grünberger B, Müller C, Kölblinger C, Peck-Radosavljevic M, Sieghart W: Advanced-stage hepatocellular carcinoma: transarterial chemoembolization versus sorafenib. Radiology 2012;263:590-599.

69 Xue TC, Xie XY, Zhang L, Yin X, Zhang BH, Ren ZG: Transarterial chemoembolization for hepatocellular carcinoma with portal vein tumour thrombus: a meta-analysis. BMC Gastroenterol 2013;13:60.

70 Zhao Y, Cai G, Zhou L, Liu L, Qi X, Bai M, Li Y, Fan D, Han G: Transarterial chemoembolization in hepatocellular carcinoma with vascular invasion or extrahepatic metastasis: a systematic review. Asia Pac J Clin Oncol 2013; 9:357-364.

71 Marrero JA, Kulik LM, Sirlin C, Zhu AX, Finn RS, Abecassis MM, Roberts LR, Heimbach JK: Diagnosis, staging and management of hepatocellular carcinoma: 2018 practice guidance by the American Association for the Study of Liver Diseases. Hepatology 2018, Epub ahead of print.

72 Nouso K, Miyahara K, Uchida D, Kuwaki K, Izumi N, Omata M, Ichida T, Kudo M, Ku Y, Kokudo N, Sakamoto M, Nakashima O, Takayama T, Matsui O, Matsuyama Y, Yamamoto K; Liver Cancer Study Group of Japan: Effect of hepatic arterial infusion chemotherapy of 5 -fluorouracil and cisplatin for advanced hepatocellular carcinoma in the Nationwide Survey of Primary Liver Cancer in Japan. Br J Cancer 2013;109:1904-1907.

73 Moriguchi M, Aramaki T, Nishiofuku H, Sato R, Asakura K, Yamaguchi K, Tanaka T, Endo M, Itoh Y: Sorafenib versus hepatic arterial infusion chemotherapy as initial treatment for hepatocellular carcinoma with advanced portal vein tumor thrombosis. Liver Cancer 2017;6:275-286.

74 Saeki I, Yamasaki T, Maeda M, Hisanaga T, Iwamoto T, Matsumoto T, Hidaka I, Ishikawa T, Takami T, Sakaida I: Evaluation of the "assessment for continuous treatment with hepatic arterial infusion chemotherapy" scoring system in patients with advanced hepatocellular carcinoma. Hepatol Res 2018;48:E87-E97.

75 Ikeda M, Shimizu S, Sato T, Morimoto M, Kojima Y, Inaba Y, Hagihara A, Kudo M, Nakamori S, Kaneko S, Sugimoto R, Tahara T, Ohmura T, Yasui K, Sato K, Ishii H, Furuse J, Okusaka T: Sorafenib plus hepatic arterial infusion chemotherapy with cisplatin versus sorafenib for advanced hepatocellular carcinoma: randomized phase II trial. Ann Oncol 2016;27:2090-2096.

76 Terashima T, Yamashita T, Arai K, Kawaguchi K, Kitamura K, Yamashita T, Sakai Y, Mizukoshi E, Honda M, Kaneko S: Response to chemotherapy improves hepatic reserve for patients with hepatocellular carcinoma and Child-Pugh B cirrhosis. Cancer Sci 2016;107:1263-1269.

77 Kudo M, Ueshima K, Yokosuka O, Ogasawara S, Obi S, Izumi N, Aikata H, Nagano H, Hatano E, Sasaki Y, Hino K, Kumada T, Yamamoto K, Imai Y, Iwadou S, Ogawa C, Okusaka T, Kanai F, Akazawa K, Yoshimura KI, Johnson P, Arai Y; SILIUS study group: Sorafenib plus low-dose cisplatin and fluorouracil hepatic arterial infusion chemotherapy versus sorafenib alone in patients with advanced hepatocellular carcinoma (SILIUS): a randomised, open label, phase 3 trial. Lancet Gastroenterol Hepatol 2018;3:424-432.

78 Vilgrain V, Pereira H, Assenat E, Guiu B, Ilonca AD, Pageaux GP, Sibert A, Bouattour M, Lebtahi R, Allaham W, Barraud H, Laurent V, Mathias E, Bronowicki JP, Tasu JP, Perdrisot R, Silvain C, Gerolami R, Mundler O, Seitz JF, Vidal V, Aubé C, Oberti F, Couturier O, Brenot-Rossi I, Raoul JL, Sarran A, Costentin C, Itti E, Luciani A, Adam R, Lewin M, Samuel D, Ronot M, Dinut A, Castera L, Chatellier G; SARAH Trial Group: Efficacy and safety of selective internal radiotherapy with yttrium-90 resin microspheres compared with sorafenib in locally advanced and inoperable hepatocellular carcinoma (SARAH): an open-label randomised controlled phase 3 trial. Lancet Oncol 2017;18:1624-1636.

79 Lencioni R, Llovet JM, Han G, Tak WY, Yang J, Guglielmi A, Paik SW, Reig M, Kim DY, Chau GY, Luca A, Del Arbol LR, Leberre MA, Niu W, Nicholson K, Meinhardt G, Bruix J: Sorafenib or placebo plus TACE with doxorubicineluting beads for intermediate stage HCC: the SPACE trial. J Hepatol 2016;64:1090-1098. 